\title{
Effect of Impeller Position and Baffle Width on Uniformity of Fe Concentration for Fortification of Baby Instant Porridge
}

\author{
Herry Santosa, Noer Handayani ${ }^{*}$ Kristinah Haryani, Bontor Sitorus, and Muhija Mawarni \\ Departement of Chemical Engineering, Faculty of Engineering, Diponegoro University, Prof. Soedarto, SH, Tembalang, \\ Semarang, 50275, Indonesia
}

\begin{abstract}
Iron deficiency (ID) is considered to be the most micro- nutritional problem, and the main cause of anaemia, called Iron Deficiency Anaemia (IDA). Nowadays, iron fortification is the most practical and priority solution for IDA alleviation. For toddler, iron fortification could be performed on complementary food of breast milk, such as instant porridge. Iron fortification was conducted using mixing and agitation method to prepare instant porridge from purple sweet potato flour. The aims of this work were to investigate the effect of impeller position and baffle width on the uniformity of iron concentration. Preparations of purple sweet potato flour and iron fortification were conducted using drying and mixing agitation method, respectively. Two independent variables, i.e. impeller position $(1,1.8,2.6,3.2 \mathrm{~cm}$ from the bottom of stirred tank) and baffle width $(1.1,1.4,1.8,2.3 \mathrm{~cm})$, were used to investigate the uniformity of iron. Iron concentration was determined by atomic absorption spectrophotometer (AAS). The results depict that impeller position $1.8 \mathrm{~cm}$ from the bottom of the stirred tank and baffle width $1.1 \mathrm{~cm}$ provide a relatively good operating condition to obtain the high level of iron uniformity.
\end{abstract}

\section{Introduction}

Vitamin A, iron, zinc and iodine have important roles to maintain body metabolism, improved health, and well-being of humans. Furthermore, iron deficiency (ID) is considered to be the most micro- nutritional problem, and the main cause of anaemia, called Iron Deficiency Anaemia (IDA) [1,2]. Children under 5 years old and women of child bearing age are the most susceptible subjects of this micronutrient malnutrition. IDA brings adverse consequences, such as lower cognitive capability and reduced immune functions of young generation in Indonesia, particularly $[3,4]$. In accordance with these serious impacts, IDA prevention has to be priority by the Government and Health Organization.

Nowadays, iron fortification is the most practical and priority solution for IDA alleviation [5,6]. For toddler, iron fortification could be performed on complementary food of breast milk, such as instant porridge. Purple sweet potato flour is one of potential ingredients for instant porridge due to its interesting colour, high level of beta carotene and prolonged storage time. Beta carotene is very useful for children as the main dietary source of vitamin A, essential for growth, and immune function [7].

Some researchers did iron fortification for many food products using various methods [8-10]. Among those, mixing and agitation is commonly procedure and widely used for food fortification is. It is also regarded as the simplest and cheapest method in food industrial
[11]. Previous works were also conducted to investigate micronutrient fortification using mixing and agitation [12-18]. However, it has some difficulties to ensure the iron uniformity. Several variables should be controlled and regulated carefully to confirm it, so that the effective and efficient method would be achieved. Therefore, further studies to increase the mixing and agitation performance are needed.

In this study, iron fortification was conducted using mixing and agitation method to prepare instant porridge. The main substance of instant porridge was purple sweet potato flour. The aim of this work was to investigate the effect of impeller position and baffle width on the uniformity of iron concentration.

\section{Materials and Method}

\subsection{Materials}

Purple sweet potatoes were obtained from local market in Indonesia. $\mathrm{FeSO}_{4} .7 \mathrm{H}_{2} \mathrm{O}$ (p.a), as iron source, was purchased from Merck. Demineralized water was produced by Processes Laboratory at Chemical Engineering Department, Diponegoro University.

\subsection{Preparation of purple sweet potato flour}

Purple sweet potato flours were conducted by drying method. The sorted purple potatoes were sliced $( \pm 1 \mathrm{~mm})$

Corresponding author: nora@undip.ac.id 
to produce thin chips, and soaked in a sodium bisulphite solution to prevent browning. The chips were dried using oven with a temperature of $40^{\circ} \mathrm{C}$ for 10 hours. The dried chips were then fed into the grinder to form smaller shape. Sweet potato flours were then obtained by sieving it with a size of 60 mesh.

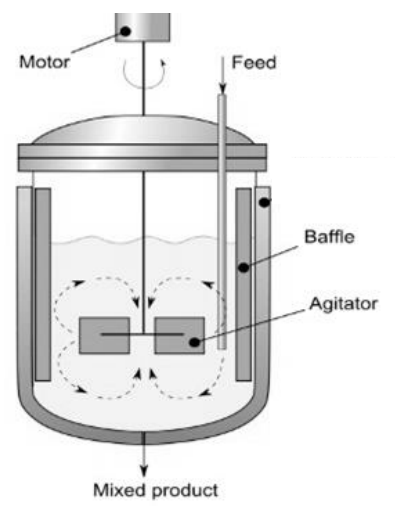

Fig. 1 Mixing tank

\subsection{Iron fortification and preparation instant porridge}

Fortification was made by using mixing agitation procedures. Iron source $\mathrm{FeSO}_{4} \cdot 7 \mathrm{H}_{2} \mathrm{O}$ was added into flours and dissolved in $100 \mathrm{ml}$ of free mineral water with ratio 1:2 water in a mixing tank with particular conditions for 15 minutes until the mixture becomes homogeneous and form slurry (Figure 1). The slurry was heated $70-80^{\circ} \mathrm{C}$ and stirred at $300 \mathrm{rpm}$. This process was carried out before gelation occurs. The impeller position $(1.0,1.8,2.6,3.2 \mathrm{~cm}$ from the bottom of stirred tank) and ratio of baffle width to tank diameter $(1.1,1.4,1.8,2.3$ $\mathrm{cm})$ were investigated as independent variables. The height of slurry and the diameter of the tank were $9 \mathrm{~cm}$ and $10 \mathrm{~cm}$, respectively. The mixtures were dried using oven with temperature of $60^{\circ} \mathrm{C}$ for 5 hours to forms flakes. Instant porridges were obtained after size reduction process, further sieved with 60 mesh sieve.

\subsection{Iron determination}

Fe concentration was analysis using atomic absorption spectrophotometer (AAS). The results will be presented in the total $\mathrm{Fe}$ concentration.

\section{Results and Discussions}

\subsection{The effect of impeller position on uniformity of iron concentration}

Variation of impeller position was carried out due to its affect on the flow pattern of slurry [19]. The pattern and motion of slurry phase influence the acceleration of diffusion mechanism to produce uniformity of concentration [20]. The effect of impeller position on iron concentration was investigated in the stirred tank. Impeller was placed at $1,1.8,2.6,3.2 \mathrm{~cm}$ from the bottom of tank. Table 1 shows the iron concentration in different sampling locations (side, top and bottom of the vessel).

Table 2. The uniformity of iron concentration with the different impeller positions

\begin{tabular}{|c|c|c|}
\hline $\begin{array}{c}\text { Position impeller } \\
\text { from the bottom } \\
\text { (cm) }\end{array}$ & $\begin{array}{c}\text { Sampling } \\
\text { position }\end{array}$ & $\begin{array}{c}\text { Fe } \\
\text { concentration } \\
\text { (mg/l) }\end{array}$ \\
\hline \multirow{4}{*}{1} & Side & 0.072 \\
\cline { 2 - 3 } & Top & 0.073 \\
\cline { 2 - 3 } & Bottom & 0.104 \\
\hline \multirow{4}{*}{1.8} & Side & 0.110 \\
\cline { 2 - 3 } & Top & 0.120 \\
\cline { 2 - 3 } & Bottom & 0.103 \\
\hline \multirow{4}{*}{2.6} & Side & 0.018 \\
\cline { 2 - 3 } & Top & 0.080 \\
\hline \multirow{3}{*}{3.2} & Bottom & 0.029 \\
\cline { 2 - 3 } & Side & 0.038 \\
\cline { 2 - 3 } & Top & 0.016 \\
\hline & Bottom & 0.080 \\
\hline
\end{tabular}

Impeller which is placed $1.8 \mathrm{~cm}$ from the bottom of stirred tank provide a better uniformity in comparison with others positions. Three sampling locations of the tank (side, top, and bottom) showed a relatively uniform of iron concentration $(0.100,0.120,0.103 \mathrm{mg} / \mathrm{l})$. This result is in a good agreement with the theory proposed by Dickey (1984) [21]. Impeller should be placed at $1 / 6$ of total fluid height. The height of total slurry in the stirred tank is $9 \mathrm{~cm}$, so that impeller could be put at 1.5 $\mathrm{cm}$ from the bottom of the tank. Thus the impeller position $1.8 \mathrm{~cm}$ (from the base of the tank) had the best performance. Impeller position which is placed too far from base will cause iron congregate on the bottom of the stirred tank (see Table 1 on impeller position at 3.2 $\mathrm{cm}$ from the base tank).

\subsection{The effect of baffle width on iron concentration}

Baffle, in the mixing systems, has a function as vortex breaker which could make an axial pattern [20]. Those, the effect of baffle width $(1.1,1.4,1.8,2.3 \mathrm{~cm})$ on iron uniformity needed to be investigated. In this study, we use number of baffle 4 , since it showed the best performance in Santosa. et al (2017) [18].

Table 2 presents the iron concentration in different sampling locations (side, top and bottom of the tank). Baffle width $1.1 \mathrm{~cm}$ had a better iron homogeneity in compare with others. The samples were taken in three different locations of the tank (side, top, and bottom) depicted a relatively uniform of iron concentration $(137.5,132.5,131.0 \mathrm{mg} / \mathrm{l})$. The proper baffle width for mixing is 10 to $21 \%$ of diameter of the tank. This study used stirred tank with the diameter of $10 \mathrm{~cm}$, so that the appropriate diameter for iron uniformity is $1.1 \mathrm{~cm}$. 
Generally, the larger width of the baffle creates the turbulence flows. However, the slurry movement could be hampered while using widely baffles and the imperfect iron distribution will be obtained (see on Table 3).

Table 3. The uniformity of iron concentration with the different baffle width

\begin{tabular}{|c|c|c|}
\hline \multirow{2}{*}{ Baffle width (cm) } & $\begin{array}{c}\text { Sampling } \\
\text { position }\end{array}$ & $\begin{array}{c}\text { Fe } \\
\text { concentration } \\
\text { (mg/L) }\end{array}$ \\
\hline \multirow{4}{*}{1.1 (B1) } & Side & 137.5 \\
\cline { 2 - 3 } & Top & 132.5 \\
\cline { 2 - 3 } & Bottom & 131.0 \\
\hline \multirow{4}{*}{1.4 (B2) } & Side & 106.0 \\
\cline { 2 - 3 } & Top & 126.5 \\
\hline \multirow{4}{*}{1.8 (B3) } & Bottom & 129.0 \\
\cline { 2 - 3 } & Side & 139.5 \\
\cline { 2 - 3 } & Top & 198.0 \\
\hline \multirow{3}{*}{2.3 (B4) } & Bottom & 121.0 \\
\cline { 2 - 3 } & Side & 153.0 \\
\cline { 2 - 3 } & Top & 157.5 \\
\hline & Bottom & 125.5 \\
\hline
\end{tabular}

\section{Conclusions}

Preparation of baby instant porridge using mixing and agitation method was conducted in this study. The results depict that impeller position $1.8 \mathrm{~cm}$ from the bottom of the stirred tank and baffle width $1.1 \mathrm{~cm}$ have the optimal condition to obtain the high level of iron uniformity.

\section{Acknowledgement}

Authors would say thank you for financial support from the Fundamental Research from Ministry of Research, Technology, and Higher Education.
1. C. R. Titaley., M. J. Dibley., Asia Pas J Clin Nutr, 24, 1 (2015)

2. B. Tripathi., K. Platel., Food Chem. 126 (2011)

3. S. Akhtar., F. M. Anjum., M. A. Anjum., Food Res. Int., 44 (2011)

4. C. Gupta., P. Chawla., P. Arora., S. K. Tomar., A. K. Singh., Food Hydrocoll., 43 (2015)

5. N. F. Krebs., M. Domellof., E. Ziegler., J. Pediatr., 167, $4(2015)$

6. J. Berger., F. T. Wieringa., A. Lacroux., M. A. Dijkhuizen., Nutr. Rev., 69 (2016)

7. E. G. Donhowe., F. Kong., Food Bioproc. Tech., 7, 2 (2014)

8. Y. Wei., M. J. I. Shohag., F. Ying., X. Yang., C. Wu, Y. Wang., Food Chem., 138 (2013)

9. W. Hei., M. J. I. Shohag., Y. Wei, Y. Feng., X. Yang., Food Chem., 141 (2013)

10. N. A. Handayani,, M. Luthfansyah, E. Krisanti, S. Kartohardjono, K. Mulia., AIP Conf. Proc., 1904, 0200531-0200538 (2017)

11. E. Betoret., N. Betoret., D. Vidal., P. Fito, Trends Food Sci. Technol., 22 (2011)

12. A. Kyritsi., C. Tzia., V. T. Karathanos.. LWT - J. Food Sci. Technol,, 44 (2011)

13. M. L. Samaniego-Vaesken., E. Alonso-Aperte., G. Varela-Moreiras., J. Food Compost. Anal., 23 (2010)

14. F. Jimenez-Colmenero., F. J. Sanchez-Muniz., B. Olmedilla-Alonso., Food Chem., 123 (2010)

15. J. L. Chavez-Servin., A. I. Castellote., M. C. LopezSabater., Food Chem., 106 (2008)

16. G. Puccio, C. Cajozzo, F. Meli., F. Rochat., D. Grathwohl., P. Steenhout., J. Nutr., 23 (2007)

17. P. Alliet., P. Scholtensc., M. Raes., K. Hensen., H. Jongen., J. -L. Rummens., J. Nutr., 23 (2007)

18. H. Santosa, K. Haryani, N. A. Handayani, H. Cahyono, Muhija, Bontor., Adv. Sci. Lett.,, 23 (2017)

19. A. Kaćunić., M. Akrap., N. Kuzmanić., Chem. Eng. Res. Des., 91, 2 (2013)

20. K. J. Myers., M. F. Reeder., J. B. Fasano., Chem. Eng. Prog., 91, 12 (2002)

21. D. S. Dickey., In Handbook of Chemical Engineering Calculations, (N.P. Chopey and T.G. Hicks Eds.), McGraw-Hill, New York, (1984)

\section{References}

